\title{
Emergence of climate change ecology
}

\author{
Sergey Venevsky \\ Department for Earth System Sciences, Tsinghua University, Beijing, China \\ venevsky@tsinghua.edu.cn
}

Manuscript to be submitted to "Global Environmental Change"

\begin{abstract}
Term "climate change ecology" is discussed. Areas of ecology, covered by the term, are described. Examples of findings of climate change ecology are given. Methods of climate change ecology are presented.
\end{abstract}

Introduction

The term "climate change ecology" is rather recent. Scopus search for this term results in only 42 articles with the term firstly mentioned in 2004 (1). Meanwhile, the leading scientific journal like Nature and Science are publishing Special Issues or sections with the title "Climate Change Ecology" (e.g. "Science" from August 2, 2013). Here, I discuss a subject of this newly appeared branch of ecology, its methods and current state.

1. What is climate change ecology

It can be defined that climate change ecology is a part of ecology dealing with climate change impacts upon terrestrial and marine ecosystems.

\subsection{Climate change}

\subsubsection{External and internal forces of climate}

Climate at a certain location is a feature of Earth described by a sequence of long period (decadal, or century) averaged climate variables with temperature, precipitation, wind speed and direction, short wave radiation and relative humidity most important variables for the atmosphere ( for the oceans the most important climate variable is sea surface temperature). Climatic variables can be considered at different time scale (larger than daily, i.e. 5-days, weekly, monthly, annually or for decades). Climate is different around the globe it may be polar, temperate, tropical (or has other subdivision) depending on temperature or may be arid or humid (depending on precipitation). Classification of Earth climates was suggested by Koeppen (2).

Climate of the Earth is controlled by external and internal forces. External driving forces for the Earth's climate are gravitation of nearest space bodies, which determine position of the planet to the Sun, and 
Solar irradiation. Climate internal driving forces are more numerous. They include gas and particle composition of the atmosphere, distribution of land and ocean masses, topography of land surface and bottom of the ocean. Especially important for providing climate suitable for life is gas content of the atmosphere. Greenhouse gases like water vapor, carbon dioxide, methane and nitrogen oxides are absorbing outgoing long wave radiation from the planet surface into outer space and, thus, keep the average temperature of the Earth being $14^{\circ} \mathrm{C}$. Humans by actively exploring Earth natural resources changing gas composition of the atmosphere. Exponentially increasing anthropogenic greenhouse gases emissions are responsible for additional warming of the atmosphere to almost $1^{\circ} \mathrm{C}$ since pre-industrial period. The observed and projected increase of average global temperature induced by humans has differential regional manifestations, including not only seasonal warming, but cooling, as well as extreme climate events like prolonged droughts or floods, hurricanes etc. Impact of climate change upon ecosystems and humans at different spatial scales at recent or at geological time steps is a subject of climate change ecology.

\subsubsection{Climate change: natural and man-made}

Quantitatively climate change is determined as long-term (decadal to millions of years) change in statistical parameters of regional or global weather patterns. Mean and spread are major statistical parameters of climate change. For instance, annual average global temperature is a main statistical parameter used in description of global climate change. It was shown that annual average global temperature had significant variation $\left(3^{\circ}-8^{\circ} \mathrm{C}\right)$ during history of the Earth. Evidence of climate change at decadal to geological time scales is confirmed by different observation sources. Temperature direct measurements from surface meteorological stations or radio balloons in troposphere allows direct record of climate change on decadal scale. Recent satellite observations allow conduction of observations of climate variables with fine spatial resolution using different proxies. Glaciers considered the best indicators of climate change in the past. Analysis of ice cores from glaciers revealed that since 3 million years glacial and interglacial cycles caused by orbital forcing were major regulators of climate change. However, data from ice cores drilled in central Greenland demonstrated that abrupt climate change during glaciation may persist without orbital forcing due to fast inner restructuring of climate system. Dendrochronology, which is focusing on width of tree rings as an indicator of dry and wet and warm and cold years is demonstrating evidence of climate change at century time scale. Palynology looks in distribution of fossil pollens reflecting pattern of past vegetation zones which were constrained by past climates.

Climatic system consists of several elements: atmosphere, ocean, biosphere and cryoshpere. Interaction of atmosphere and ocean due to transfer of heat, distributed differentially in space, creates inner climate variation. Biosphere is another important regulator of inner climate variability because of its role in global carbon and water cycle. Humans actively exploiting carbon stored in former biospheres as fossil fuel are changing gas content of the atmosphere and its radiative transfer abilities. Excessive amounts of greenhouse gases, first of all of carbon dioxide, may the reason of recent increase in global temperature named by general public as global warming, The so named "global warming", associated with change of global surface temperature, in regional realization can be seen as drying, wetting or cooling, as well as 
change in frequency of extreme weather events like hurricanes, because of complexity of interactions of elements of climate system and its highly non-linear dynamics (3).

In course of time anthropogenic and natural forcing mechanisms may change each other even at decadal time scale. This can be seen for instance in XX century, where in the beginning of century increasing trend in global surface temperature is attributed to variation of solar irradiance, while relatively quick rise in global surface temperature in the last decades of the century is associated with rapid rise in anthropogenic greenhouse emissions (4). The climate change caused by humans in the last few decades is a subject of great concern of society as consequences of climate change are already observed everywhere in biosphere and anthroposphere.

\subsection{Ecological response to recent climate change}

Impacts of recent climate change are observed almost everywhere, despite value of global surface temperature changed only to several percent to absolute value in last decades. We can divide conditionally these impacts to a) biophysical changes which related to change in chemical fluxes and stores in ecosystems of different scales from the global to local both natural and human-dominated (urban and agricultural); b) ecological changes, which include changes of abundance ranges and interactions between biological objects (organisms, populations, biomes).

\subsubsection{Biophysical changes}

1.2.1.1 Climate change and global biogeochemical cycles

\subsection{Climate change and water cycle}

Global water cycle is significantly influenced by climate. There is a general agreement in projections that global water cycle accelerates with increase of global surface temperature. However, despite of amount of fresh water available for humankind is suggested to increase, regional distribution of water is supposed to has a great disparities in space (5). This can increase vulnerability of water-stressed areas where according to several estimates leaves almost one third of human population of the Earth.

\subsection{Climate change and carbon cycle}

Alterations of global carbon cycle are closely related to climate change. Study of such alterations constitutes a core of climate change ecology. Anthropogenic carbon dioxide emissions are affecting climate due to greenhouse effect. Around half of these emissions are absorbed by oceans and marine and land ecosystems currently, while second half is gradually accumulated in the atmosphere. The absorbing ability of the ocean and the ecosystems are climate sensitive, so that increase of global surface temperature may decrease global absorption of carbon from the atmosphere and accelerate climate change even in the nearest future (year 2050 see (6)).

\subsection{Climate change and nitrogen cycle}

Humankind accelerates global nitrogen cycle by industrial production of fertilizers to solve food problem. This acceleration, however, has significant direct effect on global carbon cycle, especially to absorbing abilities of the biosphere. Question of mitigation of climate change by artificial controlling of nitrogen 
cycle, however, is open due to counterbalancing negative effects of euthropication and global acidification of terrestrial and aquatic ecosystems (7).

\subsubsection{Climate change and terrestrial ecosystems}

\subsubsection{Climate change and natural terrestrial ecosystems}

Research of impact of climate change to terrestrial ecosystems is not new. Simultaneous observation records for weather and changes in phenologies, life cycles and ranges for birds, animals, herbs and trees are coming back to 1700 in Northern Europe. Especially, charismatic taxons like butterflies or birds have well documented responses of body size, reproductive functions and ranges to climate variation.

Now days, the number of published studies, observational or experimental or modelling, relating climate change to terrestrial ecosystems is increasing exponentially since 2003 (see (8)).

Mostly these studies orient to phenological responses to climate change. Plants as primary producers in terrestrial ecosystems are in major focus of phenological observations. So, it was observed using remote sensing that normalized difference vegetation index (NDVI), which describes summer photosynthetic activity, was increasing in the Northern Hemisphere during 1981-1991 in line with increase of the hemisphere average surface temperature (9). On-ground observations in the network of European Phenological Botanical Gardens revealed lengthening of growing season to 10.8 days in the period 19531993 (10) as a response to global warming.

\subsubsection{Climate change and agricultural ecosystems}

Projected climate change can significantly influence crop production mainly due to availability of water. Combination with rapid growth of population in some areas makes climate change a major threat for food security. So, an analysis of climate risks to food security conducted on scenarios for twenty global circulation models till year 2030 confirmed that regions of South Africa and South Asia will most likely suffer from climate induced drop for important crop yields, which will lead to food insecurity for their fast growing populations (11).

\subsubsection{Climate change and aquatic ecosystems}

\subsubsection{Climate change and marine ecosystems}

Although there is a clear bias towards study climate change impact to terrestrial ecosystems, phenological response of marine species also got attention recently. For example, Arctic seabird Uria lomvia, has advanced its egg-laying date few days at its southern boundary (Hudson Bay). The change of date is closely correlated to change in sea-ice cover (12).

\subsubsection{Climate change and freshwater ecosystems}

Freshwater ecosystems demonstrate phenological response for climate change similar to terrestrial ecosystems. So, phytoplankton bloom, moved gradually by nineteen days earlier in the period 1962 to 2002 in a lake in North-Western USA, while zooplankton development showed more erratic behavior (13). 


\subsubsection{Ecological changes per se}

\subsubsection{Climate change and biogeography}

The coherent signals of climate change on broad scale plant and animal communities are seen now days almost everywhere. One can expect poleward and upward shifts in warming regions and opposite direction development in cooling regions with restructuring of communities. Such studies at communities level are however rather rare. The theoretical models as a generalization of communities use biome concept or plant functional type concept related to it (14). However, observations confirming broad scale redistribution of biomes are rather rare. Here, observations of tree line change play major supporting tool for climate driven biogeography impacts. So, northwards migration of tree line in warm decades of 1990s are seen in Scandinavia (15) eastern Canada (16) and in Europe (17).

\subsubsection{Climate change and spatial distribution of species}

There are numerous confirmations to climate change related species ranges. Shifts in species abundance ranges are seen recently at polar latitudes, in Northern Hemisphere temperate species, in tropical species, mountain species and marine species (see review of (8)). It should be noted, however, that whole species range/climate change studies are rather rare. Such studies focus at the moment to plants, mammals and amphibian.

\subsubsection{Climate change and interaction between species}

Species involved in trophic networks have different climate tolerances, variety of phenological responses to climate change. This may influence their interactions in prey-predator relationships. Climate change related asynchronies in timing of appearance/ senescing of species of related trophic interactions may bring some species to the verge of extinctions or benefit them. Studies focusing on impact of climate change to interactions of species are, however, still rare and related mainly to plants-insects or plantsbirds interactions. So, range contractions or expansions of common butterfly Enphydria Editha were documented in relation with the time of blooming or senescing of nectar flowers (18). Flower life events in its turn were shown to be related to droughts or low snow pack years (18).

2. Methods of climate change ecology

Climate change ecology by definition should focus on living objects at different spatial scales, which function at different time steps. This requires combination of all available in ecology methods from traditional (as observations) to most recent (like large scale terrestrial ecosystem modelling).

\subsection{Observations}

\subsubsection{Field observations}

Analysis of climate change impact upon ecosystems requires systematic laborious monitoring. It is now widely accepted that so named research observatories networks are suitable for these purposes. Typically, such research networks are focusing on some rather large scientific questions (like status of carbon in an ecosystem, or status of biodiversity in an). Most famous like Carbo-North, LTER and FLUXNET are building 
international networks based on pre-defined principles. Such principle can be for example using watersheds of different level if we concentrating on soil moisture alterations due to climate change (19).

\subsubsection{Set experiments: FACE}

Rising level of $\mathrm{CO}_{2}$ in the atmosphere, which comes alone with climate change, may heavily influence plant physiology and accelerate or decelerate further global warming. Free-air $\mathrm{CO}_{2}$ experiment allow study of carbon dioxide enrichment on plant and ecosystem growth in natural conditions. The experiment is going already more than twenty years in different ecosystems types around the world. It was confirmed in the course of the experiment that above-ground production of plants is increasing in conditions of elevated $\mathrm{CO}_{2}$, thus, making negative feedback to climate change. The effect, however, depends on functional type of ecosystem. Trees are reacting to carbon dioxide increase more than herbaceous vegetation (20).

\subsection{Remote sensing}

Satellite remote sensing measuring entering and leaving flux of radiation from top of the atmosphere is one of the most powerful tools in climate change ecology. NASA at the moment uses 14 satellites of different types of orbits (sun-synchronous and geo-synchronous) with different type of sensors (passive sensors, which record naturally occurring electromagnetic radiation at top of the atmosphere and active sensors which emit electromagnetic radiation toward the Earth and measure its scattering/reflection. (http:/earthobservatory.nasa.gov). Satellite remote sensing allowed to study large scale areas and make findings which cannot be done by modelling or field observations. An example is consequence of global sea- rise, which cannot be detected by the models at the moment (21).

\subsection{Geo-spatial and statistical analysis}

Statistical analysis of time series plays key role in quantitative climate change ecology. So, two thirds of all studies related to climate change impacts to marine ecosystems are studying statistical relationships between climate drivers and quantitative indicators of the ecosystems (22). Visualization using geoinformation systems is another important tool in climate change studies. Analysis of thirty visualizations for climate change impacts in Australia with stakeholders reveals high effectiveness of these tools for understanding of climate change.

\subsection{Process-based modelling}

\subsubsection{Landscape scale modeling}

Recent development of computer technics and systematic field observations made it possible to describe certain features of functioning of terrestrial and marine ecosystems at landscape scale as a set of related processes described by physical (e.g. mass conservation), chemical (e.g. kinetic) and biological equations (e.g. Lotka - Volterra). Outcome of response to climate change can be simulated using system of these equations (23). Examples of such models are forest gap models which explicitly simulate process of tree growth for focused species, competition for light, water and space with favorite outcome for some trees and dying of other trees and opening the gap in the canopy. Processes of growth, competition and 
mortality are all climate specific. Thus, impact of climate change in form of composition of forest stand, above ground and underground biomass can be directly estimated by these simulation models

\subsubsection{Continental scale and global modelling}

The most important goal of climate change ecology is an understanding of functioning of Earth as a separate ecosystem, where interaction of biosphere, atmosphere, hydrosphere and oceans is considered. This requires using of modelling objects of continental or global scale. An example of modelling object of continental scale is a grid cell of dynamic global vegetation models (14), which is seen in these models as a separate ecosystem situated in terrestrial rectangle size of 1 to $1 \mathrm{~km}$ or 50 by $50 \mathrm{~km}$. Grid cell is described as a set of percentage cover of certain functional types of vegetation (like boreal evergreen or grassland or tropical evergreen) with related carbon and water pools and fluxes. Listed grid cell ecosystem indicators are all climate sensitive. Thus, global or continental scale vegetation types distribution with associated pools and fluxes can be simulated as an outcome of global or continental climate change scenarios.

3. Current state and possible future trends in climate change ecology

Climate change ecology appeared to become research field ell established in recent decades. Future trends in climate change ecology will emerge as more close fusion of field and remote sensing observations as well as statistical and process-based models at fine spatial and temporal resolution. This will be secured by use of recently developed supercomputers and micro computational technologies.

\section{Acknowledgments}

This work was supported by the National Natural Science Foundation of China (31570475).

\section{References}

1. Forchhammer MC \& Post E (2004) Using large-scale climate indices in climate change ecology studies. Population Ecology 46(1):1-12.

2. Wladimir. K \& Alfred W (2005) The Climates of the Geological Past (Borntraeger, Stuttgart).

3. Shepherd TG (2014) Atmospheric circulation as a source of uncertainty in climate change projections. Nature Geoscience 7(10):703-708.

4. Stott PA, et al. (2000) External control of 20th century temperature by natural and anthropogenic forcings. Science 290(5499):2133-2137.

5. Oki T \& Kanae S (2006) Global hydrological cycles and world water resources. Science 313(5790):1068-1072.

6. Cox PM, Betts RA, Jones CD, Spall SA, \& Totterdell IJ (2000) Acceleration of global warming due to carbon-cycle feedbacks in a coupled climate model. Nature 408(6809):184-187.

7. Gruber N \& Galloway JN (2008) An Earth-system perspective of the global nitrogen cycle. Nature 451(7176):293-296.

8. Parmesan C (2006) Ecological and evolutionary responses to recent climate change. in Annual Review of Ecology, Evolution, and Systematics, pp 637-669. 
9. Myneni RB, Keeling CD, Tucker CJ, Asrar G, \& Nemani RR (1997) Increased plant growth in the northern high latitudes from 1981 to 1991. Nature 386(6626):698-702.

10. Menzel A (2000) Trends in phenological phases in Europe between 1951 and 1996. International Journal of Biometeorology 44(2):76-81.

11. Lobell DB, et al. (2008) Prioritizing climate change adaptation needs for food security in 2030. Science 319(5863):607-610.

12. Gaston AJ, Gilchrist HG, \& Hipfner JM (2005) Climate change, ice conditions and reproduction in an Arctic nesting marine bird: Brunnich's guillemot (Uria lomvia L.). Journal of Animal Ecology 74(5):832-841.

13. Winder M \& Schindler DE (2004) Climate change uncouples trophic interactions in an aquatic ecosystem. Ecology 85(8):2100-2106.

14. Sitch S, et al. (2003) Evaluation of ecosystem dynamics, plant geography and terrestrial carbon cycling in the LPJ dynamic global vegetation model. Global Change Biology 9(2):161-185.

15. Kullman L (2001) 20th Century climate warming and tree-limit rise in the Southern Scandes of Sweden. Ambio 30(2):72-80.

16. Lescop-Sinclair K \& Payette S (1995) Recent advance of the arctic treeline along the eastern coast of Hudson Bay. Journal of Ecology 83(6):929-936.

17. Meshinev T, Apostolova I, \& Koleva E (2000) Influence of warming on timberline rising: A case study on Pinus peuce Griseb. in Bulgaria. Phytocoenologia 30(3-4):431-438.

18. Thomas CD, Singer MC, \& Boughton DA (1996) Catastrophic extinction of population sources in a butterfly metapopulation. American Naturalist 148(6):957-975.

19. Bogena H, Schulz K, \& Vereecken H (2006) Towards a network of observatories in terrestrial environmental research. Advances in Geosciences 9:109-114.

20. Ainsworth EA \& Long SP (2005) What have we learned from 15 years of free-air $\mathrm{CO} 2$ enrichment (FACE)? A meta-analytic review of the responses of photosynthesis, canopy properties and plant production to rising CO2. New Phytologist 165(2):351-372.

21. Yang J, et al. (2013) The role of satellite remote sensing in climate change studies. Nature Climate Change 3(10):875-883.

22. Brown CJ, et al. (2011) Quantitative approaches in climate change ecology. Global Change Biology 17(12):3697-3713.

23. Allen CD, et al. (2010) A global overview of drought and heat-induced tree mortality reveals emerging climate change risks for forests. Forest Ecology and Management 259(4):660-684. 